\title{
Release of Vasoactive Intestinal Peptide in Mouse Cerebral Cortex: Evidence for a Role of Arachidonic Acid Metabolites
}

\author{
Jean-Luc Martin and Pierre J. Magistretti \\ Département de Pharmacologie, Centre Médical Universitaire 1211 Geneva 4, Switzerland
}

In rodent cerebral cortex, vasoactive intestinal peptide (VIP) is contained in a homogeneous population of radially oriented bipolar interneurons. We have observed that 4-aminopyridine (4-AP), a $\mathrm{K}^{+}$-channel blocker, promotes a concentration- and $\mathrm{Ca}^{2+}$-dependent release of VIP from mouse cerebral cortical slices, with a significant effect already observed at $50 \mu \mathrm{M}$. Over $70 \%$ of VIP release elicited by 4-AP is blocked by $2 \mu \mathrm{M}$ tetrodotoxin (TTX). Mepacrine, an inhibitor of phospholipase $A_{2}\left(P L A_{2}\right)$ activity and hence of arachidonic acid (AA) formation from membrane phospholipids, markedly inhibits (IC50 of approximately $15 \mu \mathrm{M}$ ) the release of VIP evoked by 4-AP. The inhibitory effect of mepacrine is not additive to that of TTX, thus indicating an involvement of PLA activation in the TTX-sensitive component of the 4-AP-evoked release. As a corollary, melittin $(0.1-10 \mu \mathrm{g} / \mathrm{ml})$, a PLA activator, promotes VIP release. Inhibition of AA metabolites of the lipoxygenase pathway by nordihydroguaiaretic acid, 5,8,11,14-eicosatetranoic acid, and caffeic acid results in a concentration-dependent inhibition of VIP release evoked by 4-AP.

This set of observations indicates for the first time that the formation of AA metabolites of the lipoxygenase pathway plays a role in the release of a peptide in the mammalian CNS. Furthermore, these observations together with the previously reported potentiation by prostaglandins of the increase in cyclic AMP elicited by VIP in mouse cerebral cortex (Schaad et al., 1987) indicate that AA metabolites may act at both the presynaptic (lipoxygenase metabolites) and the postsynaptic (cyclooxygenase metabolites) levels to increase the "throughput" or "strength" of VIP-containing circuits in the rodent neocortex.

Vasoactive intestinal peptide (VIP) is a 28 -amino-acid polypeptide originally isolated from porcine duodenum by Said and Mutt (1970). VIP immunoreactivity has subsequently been demonstrated outside the gastrointestinal tract, including the PNS and the CNS (Larsson et al., 1976; Lorén et al., 1979). In the rodent CNS, VIP is highly concentrated in the cerebral cortex, where it is contained in a homogeneous population of in-

Received Oct. 19, 1988; accepted Nov. 8, 1988.

P.J.M. is the recipient of a Research Career Development Award (START) from Fonds National Suisse de la Recherche Scientifique (FNRS). This work was supported by FNRS Grant No. 3.357.0-86 to P.J.M. The authors are grateful to Dr. $\mathrm{K}$. Rose for his assistance in the HPLC analysis. They also wish to thank Ms. Nathalie Pellegrinelli for skillful technical assistance, Ms. Sylvianne Bonnet for expert secretarial help, and Mr. Fred Pillonel for graphical work.

Correspondence should be addressed to Pierre J. Magistretti at his present address: Institut de Physiologie, Université de Lausanne, 7 Rue du Bugnon, 1005 Lausanne, Switzerland.

Copyright (C) 1989 Society for Neuroscience $0270-6474 / 89 / 072536-07 \$ 02.00 / 0$ tracortical and radially oriented bipolar neurons (Lorén et al. 1979; Morrison et al., 1984). In the cerebral cortex VIP exerts several cellular actions such as the stimulation of cyclic AMP (cAMP) formation (Quik et al., 1978; Magistretti et al., 1984) and of glycogenolysis (Magistretti et al., 1981) as well as alterations in the spontaneous firing rate of identified neurons (Phillis et al., 1978; Ferron et al., 1985). VIP interacts synergistically with norepinephrine to increase cAMP levels in mouse cerebral cortex (Magistretti and Schorderet, 1984, 1985). Recent evidence indicates that this synergism is mediated by prostaglandins (Schaad et al., 1987). The release of VIP can be evoked by electrical and $\mathrm{K}^{+}$-evoked depolarizations in a $\mathrm{Ca}^{2+}$-dependent manner (Besson et al., 1982; Wang et al., 1983, 1985). In an attempt to characterize further the position of VIP-containing neurons in cerebral cortical circuitry and their presynaptic regulation, we have examined the molecular mechanisms that underlie the release of VIP evoked by the organic cation 4-aminopyridine (4-AP).

4-AP is a blocker of 2 voltage-sensitive $\mathrm{K}^{+}$currents, the delayed rectifier and the A-current, a transient outward current (Thompson, 1977; Gustafsson et al., 1982; Segal et al., 1984; Rogawski, 1985). Blockade of the delayed voltage-sensitive $\mathrm{K}^{+}$ channel prolongs the action potential at nerve terminals by inhibiting the repolarization phase. This action results in an enhancement of neurotransmitter release because of the increase in the open time of voltage-sensitive calcium channels in the nerve terminal membrane (Lemeignan, 1972; Jankowska et al., 1977; Heuser et al., 1979; 'Thesleff, 1980). A-currents play an important role in controlling excitability at voltages near the resting potential (Rogawski, 1985) by preventing small depolarizing stimuli to reach threshold and trigger action potentials. Therefore, by blocking voltage-sensitive $\mathrm{K}^{+}$channels, 4-AP may also increase the inflow of $\mathrm{Ca}^{2+}$ into nerve terminals and stimulate neurotransmitter release. Finally, evidence has been presented for a direct effect of 4-AP on $\mathrm{Ca}^{2+}$ channels, favoring $\mathrm{Ca}^{2+}$ inflow (Lundh and Thesleff, 1977; Illes and Thesleff, 1978; Rogawski and Barker, 1983).

In the present set of investigations we have examined the release of VIP from mouse cerebral cortical slices elicited by 4-AP and have observed that (1) 4-AP promotes a concentration-dependent release of VIP in a $\mathrm{Ca}^{2+}$-dependent manner, (2) over $70 \%$ of 4 -AP-evoked VIP release is blocked by tetrodotoxin (TTX), and (3) the TTX-sensitive component of VIP release evoked by 4-AP is mediated by arachidonic acid (AA) metabolites of the lipoxygenase pathway.

\section{Materials and Methods}

Release experiments. Swiss male albino mice were used throughout this study. They were maintained in an alternating $12 \mathrm{hr}$ light/12 hr dark 
cycle and had free access to food and water. Cerebral cortical slices were prepared as follows (Magistretti et al., 1981). Mice were decapitated and their brains rapidly removed. The cerebral cortex was then dissected on ice and immediately placed in a modified Krebs-Ringer bicarbonate buffer, pH 7.4 (KRG) containing (in mM concentrations): $\mathrm{NaCl}, 120$; $\mathrm{KCl}, 3 ; \mathrm{CaCl}_{2}, 2.6 ; \mathrm{MgSO}_{4}, 0.67 ; \mathrm{KH}_{2} \mathrm{PO}_{4}, 1.2$; glucose, $3 ; \mathrm{NaHCO}_{3}$, 27.5 , previously gassed with $\mathrm{O}_{2} / \mathrm{CO}_{2}(95: 5)$. The dissected cortices (1 cortex for approximately 8 tubes) were then placed on a McIlwain tissue chopper, their ventral aspect facing the chopping plate, and $250 \mu \mathrm{m}$ slices were prepared. The plate was then rotated by $90^{\circ}$, and the cortices were cut again. The slices were then resuspended (using a glass pipette) in $\mathrm{KRG}$ and incubated for $90 \mathrm{~min}$ at $37^{\circ} \mathrm{C}$ under continuous gassing $\left(\mathrm{O}_{2}: \mathrm{CO}_{2}, 95: 5\right)$ and vigorous shaking. The medium was replaced every 30 min with fresh KRG. At 90 min, after the last medium replacement, $450 \mu \mathrm{l}$ of the slice suspension (1-2 mg of proteins) were distributed into Eppendorf tubes. Drugs $(25 \mu l)$ were then added for $4 \mathrm{~min}(4-\mathrm{AP}$ and $\mathrm{K}^{+}$). The inhibitors were added 2 min prior to the depolarizing agents. At the end of the incubation, the tubes were centrifuged for $2 \mathrm{~min}$ at $9980 \times g$; an aliquot of the supernatant was removed, lyophilized in a Speed-Vacuum concentrator (Savant Instrument), and resuspended in radioimmunoassay (RIA) buffer. VIP released in the supernatant was mcasurcd by RIA as described by Martin et al. (1986). The remaining supernatant was removed, and $750 \mu \mathrm{l}$ of $1 \mathrm{M} \mathrm{CH}_{3} \mathrm{COOH}$ were added to the pellet for extraction of VIP from tissue. The solution was boiled for $15 \mathrm{~min}$ and sonicated. Aliquots of $20 \mu \mathrm{l}$ were tested for protein concentration as described by Lowry et al. (1951). The tubes were then centrifuged for 2 min $(9980 \times g)$, an aliquot of the supernatant was diluted and lyophilized, and VIP tissue content was measured by RIA (Martin et al., 1986). For the RIA procedure, samples were incubated for $2 \mathrm{~d}$ at $4^{\circ} \mathrm{C}$ using a well-characterized molecular species of ${ }^{125} \mathrm{IVIP}$, i.e., (mono $\left.{ }^{125} \mathrm{I}\right)$ iodo-Tyr $\left.{ }^{10}, \mathrm{MetO}^{17}\right)$-VIP, which is monoiodinated on $\mathrm{Tyr}$ 10 and oxidized on Met 17 (Martin et al., 1986). The lower limit of detection of this RIA is $3 \mathrm{pg}$. No cross-reactivity is observed either with other peptides sharing structural homologies with VIP, such as peptide having $\mathrm{N}$-terminal histidine and $\mathrm{C}$-terminal isoleucine amide (PHI), secretin 5-27, glucagon, GRF 1-44 $\mathrm{NH}_{2}$, or GRF 1-28 OH, or with peptides unrelated to VIP, such as somatostatin (SS-14), neurotensin, bombesin, leu-enkephalin, or met-enkephalin. The intra-assay variation of the RIA is $8 \%$, and the interassay variation $10.6 \%$. Statistical analysis was performed using the Student's $t$-test.

VIP was purchased from Professor V. Mutt, Department of Biochemistry II, Karolinska Institute, Stockholm. Rabbit anti-VIP antiserum was from Amersham International. Caffeic acid, indomethacin, melittin, and mepacrine were purchased from Sigma (St. Louis, MO), 4-AP from Merck (Darmstadt, FRG), and 5,8,11,14-eicosatetraenoic acid (ETYA), 5(S)-hydroperoxyeicosatetraenoic acid (HPETE), 12(S)HPETE, and TTX from Calbiochem (La Jolla, CA).

Reverse-phase high-performance liquid chromatography analysis of VIP extracts. Tissue acid extracts $\left(1 \mathrm{M} \mathrm{CH}_{3} \mathrm{COOH}\right)$ containing VIP were further purified through a Sep-pack $\mathrm{C}_{18}$ cartridge previously washed with $5 \mathrm{ml}$ of $\mathrm{MeOH}$ and pre-equilibrated with $10 \mathrm{ml}$ of $10 \% \mathrm{CH}_{3} \mathrm{CN}$ vol/ vol in 1\% TFA-tetraethylammonium (TEA) (pH 2.5). The column was then washed with $5 \times 2 \mathrm{ml}$ of $10 \% \mathrm{CH}_{3} \mathrm{CN}$ in $1 \%$ TFA-TEA (pH 2.5), and VIP was eluted with $2 \mathrm{ml}$ of $60 \% \mathrm{CH}_{3} \mathrm{CN}$ in $1 \%$ TFA-TEA (pH 2.5 ). The volume of the eluted product was reduced under $\mathrm{N}_{2}$ flux and then passed through a $0.45 \mu \mathrm{m}$ Millipore column. Further purification of the product was performed on a Waters reverse-phase high-performance liquid chromatography (RP-HPLC) system using a MachereyNagel $C_{8}$ column $(5 \mu \mathrm{m}$ diameter, $300 \AA$ pore size, end capped $0.4 \times$ $25 \mathrm{~cm}$ ). The equilibrated column was first eluted isocratically with $75 \%$ of $0.1 \%$ TFA and $25 \%$ of $90 \% \mathrm{CH}_{3} \mathrm{CN}$ (in $0.1 \%$ TFA) at a flow rate of $0.6 \mathrm{ml} / \mathrm{min}$. After $5 \mathrm{~min}$, a linear gradient of $90 \% \mathrm{CH}_{3} \mathrm{CN}$ (in $0.1 \%$ TFA) was started, $25 \%$ to $45 \%$ over 40 min. Porcine VIP was detected at $214 \mathrm{~nm}$. The samples were collected in $100 \mu \mathrm{lof} 1 \mathrm{mg} / \mathrm{ml} \mathrm{BSA}$ and

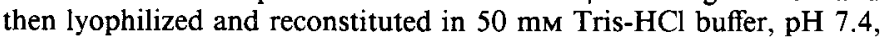
containing $5 \mathrm{mM} \mathrm{MgCl}_{2}, 2 \mathrm{~mm}$ EGTA, $0.2 \% \mathrm{BSA}$, and $0.1 \mathrm{~mm}$ bacitracin. VIP-like immunoreactivity in an aliquot of each fraction was assayed by RIA.

\section{Results}

An RP-HPLC procedure was used to characterize VIP-like immunoreactivity (VIP-LI) extracted from mouse cerebral cortical slices using conditions described in Materials and Methods. The RP-HPLC purification followed by determination of VIP-LI

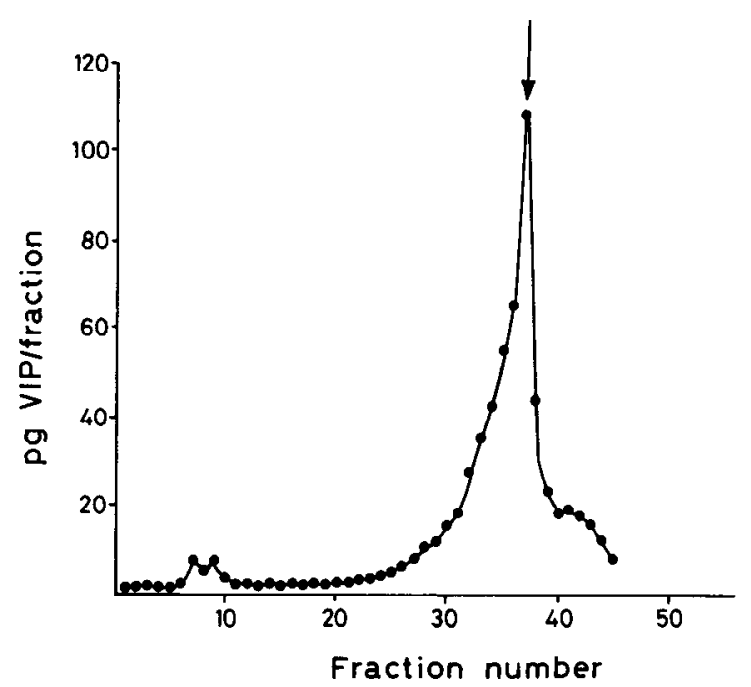

Figure 1. RP-HPLC characterization of VIP tissue content extracts. Mouse cerebral cortical slices corresponding to a protein concentration of $1.78 \mathrm{mg}$ were extracted, chromatographed on a Sep-pack $\mathrm{C}_{18}$ cartridge, and passed through a $0.45 \mu \mathrm{m}$ Millipore column. The extracted product was the analyzed by RP-HPLC as described in Materials and Methods. Fractions of $0.6 \mathrm{ml} / \mathrm{min}$ were collected in $100 \mu \mathrm{l}$ of $1 \mathrm{mg} / \mathrm{ml} \mathrm{BSA}$, lyophilized, and assayed for their VIP-LI content by RIA (Martin et al., 1986). The elution position of native VIP, determined by absorbance at $214 \mathrm{~nm}$, is indicated by the arrow and corresponds to $37 \mathrm{~min}$.

tissue content of each fraction by RIA shows a single peak eluting at a retention time of $37 \mathrm{~min}$ (Fig. 1). The position (on the same gradient) of native VIP monitored for absorbance at $214 \mathrm{~nm}$ corresponds to $37 \mathrm{~min}$. No difference between the elution position of native VIP and VIP-LI extracted from cerebral cortex was observed. The short tail appearing at 42 min may be explained either by the presence in the extract (at the C-terminal) of desamidated VIP, which is expected to elute at a longer retention time than does native VIP, or by the rather small quantity (3-4 ng) of VIP passed through the column.

The release of VIP evoked by 4-AP was examined. As shown in Figure 2, 4-AP promotes a concentration-dependent release of VIP, with a significant effect already observed at $50 \mu \mathrm{M}$. At $1 \mathrm{mM}, 4-A P$ increases by almost 6 -fold the basal release of VIP. We have also observed that 4-AP enhances the release of VIP elicited by small depolarizing stimuli, such as those achieved by raising the extracellular $\mathrm{K}^{+}$concentration to 7 or $10 \mathrm{~mm}$ (Table 1). These $\mathrm{K}^{+}$concentrations are ineffective $(7 \mathrm{~mm})$ or marginally effective (10 $\mathrm{mm}$ ) per se in stimulating VIP release (Table 1).

The 4-AP-evoked release of VIP is $\mathrm{Ca}^{2+}$-dependent, as indicated by the complete block observed after addition to the medium of the $\mathrm{Ca}^{2+}$ channel blocker $\mathrm{Co}^{2+}$ at a concentration of 5 $\mathrm{mM}$ : basal release $(\%$ of VIP content $)=0.232 \pm 0.02 ; 4-\mathrm{AP}(1$ $\mathrm{mM})=1.7 \pm 0.07 ;$ and $4-\mathrm{AP}(1 \mathrm{mM})+\mathrm{Co}^{2+}(5 \mathrm{mM})=0.221$ $\pm 0.02 . \mathrm{Mn}^{2+}$, another inorganic $\mathrm{Ca}^{2+}$ channel blocker, also significantly inhibited (by $69 \%$ at $1 \mathrm{mM}$ ) the release of VIP evoked by 4-AP: basal release ( $\%$ of VIP content) $=0.223 \pm$ 0.03 ; 4-AP $(1 \mathrm{mM})=1.11 \pm 0.07$; and $4-\mathrm{AP}(1 \mathrm{mM})+\mathrm{Mn}^{2+}$ $(1 \mathrm{~mm})=0.499+0.02$.

The release of VIP evoked by 4-AP most likely results from an increase in impulse activity in the slices. However, depolarization of VIP-containing nerve terminals associated with regenerative $\mathrm{Ca}^{2+}$ currents cannot be excluded (Llinas et al., 1976; Lundh and Theslefr, 1977; Molgo et al., 1980; Dolezal and 


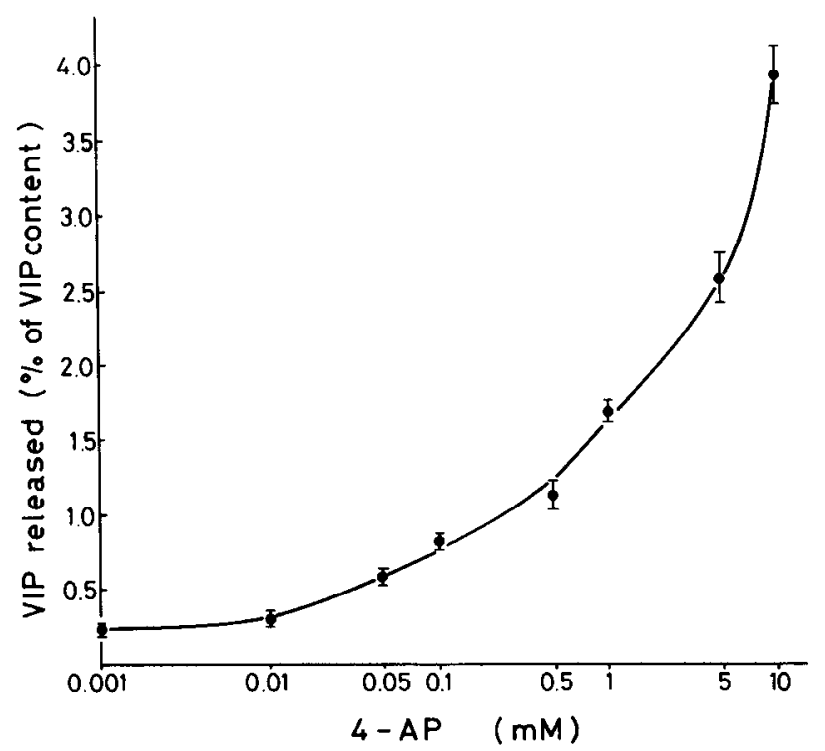

Figure 2. Effect of increasing concentrations of 4-AP on basal VIP release. Mouse cerebral cortical slices were incubated as described in Materials and Methods. VIP released is expressed as percentages of VIP tissue content. Results are the means \pm SEM of 4 determinations in each of 2 separate experiments, except for basal VIP release $(n=8$ in each experiment). Basal VIP release was $0.301 \pm 0.021 \% ; n=16$. Absolute values of VIP released into the medium and of VIP content were $11.99 \pm 0.75 \mathrm{pg} / \mathrm{mg}$ prot $(n=16)$ and $4050.48 \pm 158.23 \mathrm{pg} / \mathrm{mg}$ prot $(n=16)$, respectively.

Tucek, 1983). In an attempt to determine the relative contribution of these 2 mechanisms, we examined the effect of TTX, a blocker of voltage-sensitive $\mathrm{Na}^{+}$channels on the release of VIP evoked by 4-AP. As indicated in Figure 3, TTX at $2 \mu \mathrm{M}$, a concentration previously shown to completely block voltagesensitive $\mathrm{Na}^{+}$channels (Moore et al., 1967; Ulbricht, 1974; Alvarez-Leefmans and Miledi, 1980; Dolezal and Tucek, 1983) and therefore the propagation of action potentials, markedly inhibits the release of VIP induced by 4 -AP $(73.97 \pm 1.71 \% ; n$

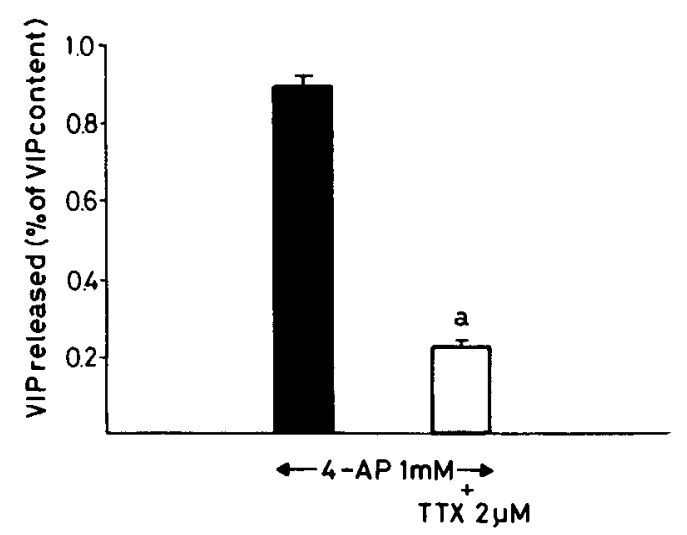

Figure 3. Inhibition by TTX of 4-AP evoked release of VIP. Mouse cerebral cortical slices were incubated as described in Materials and Methods. These results are the means \pm SEM of 7-8 determinations in each of 2 separate experiments. Basal VIP release was $0.208 \pm 0.013 \%$ $(n=7)$. Absolute values of VIP released into the medium and of VIP content were $8 \pm 0.56 \mathrm{pg} / \mathrm{mg}$ prot $(n=7)$ and $3841.43 \pm 99.31 \mathrm{pg} / \mathrm{mg}$ prot $(n=7)$, respectively. No effect on basal VIP release was observed with $2 \mu \mathrm{M}$ TTX, e.g.: basal VIP release $=0.309 \pm 0.034 \%(n=4)$; TTX $(2 \mu \mathrm{M})$ alone $=0.277 \pm 0.013 \%(n=4)$. $a$, Significantly different from 4-AP-induced VIP released $(p<0.0005)$.

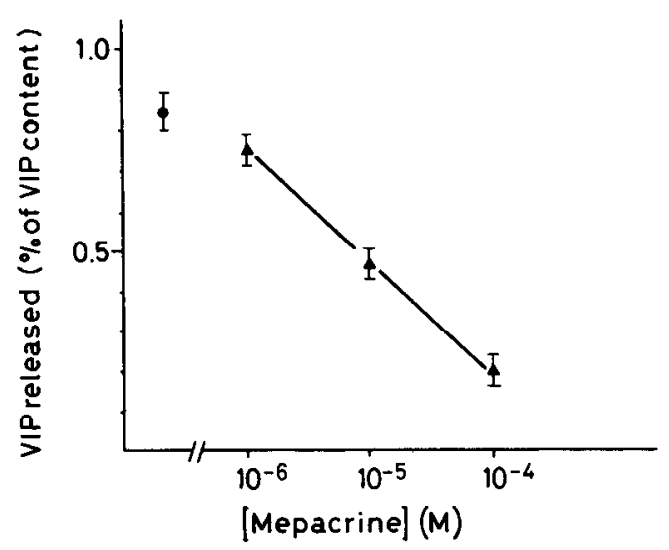

Figure 4. Concentration-response curve of the inhibition by mepacrine of 4-AP-evoked VIP release. Mouse cerebral cortical slices were incubated as described in Materials and Methods. Results are the means \pm SEM of 6 determinations from one experiment, repeated once with similar results. These results are expressed as percentages of VIP tissue content. Basal VIP release was $0.201 \pm 0.022 \%, n=7$. Absolute values of VIP released into the medium and of VIP content were $7.24 \pm 0.096$ $\mathrm{pg} / \mathrm{mg}$ prot $(n=7)$ and $3544.8 \pm 139 \mathrm{pg} / \mathrm{mg}$ prot $(n=7)$, respectively. Mepacrine $(50 \mu \mathrm{M})$ did not affect basal VIP release, e.g.: basal VIP release $=0.267 \pm 0.013 \%(n=5)$; mepacrine $(50 \mu \mathrm{M})$ alone $=0.262 \pm 0.012 \%$ $(n=6)$.

$=8$ ). This observation suggests that approximately $70 \%$ of VIP release is dependent on the presence of action potentials, whereas $30 \%$ of the release may reflect a direct action of 4-AP on VIP terminals.

In a series of experiments in which we set out to examine the molecular mechanism(s) involved in the release of VIP, we made the observation that mepacrine, an inhibitor of phospholipase $\mathrm{A}_{2}$ (PLA $\mathrm{P}_{2}$ ) activity, inhibited in a concentration-dependent manner the release of VIP evoked by $4-\mathrm{AP}$, with an $\mathrm{IC}_{50}$ of $15 \mu \mathrm{M}$ (Fig. 4), without affecting basal release (legend for Fig. 4). Me-

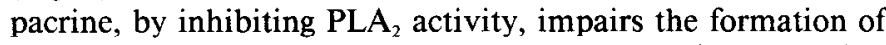
AA and hence of its metabolites (Irvine, 1982). This observation indicates that inhibition of $\mathrm{PLA}_{2}$ activity and of AA formation interferes with the expression of the release process. It should, however, be noted that mepacrine can act on other target enzymes (Chang et al., 1987). In order to further pinpoint an involvement of PLA $A_{2}$ in the release of VIP, we tested melittin,

$\begin{array}{lll}\begin{array}{l}\text { Table 1. Effect of 4-AP (1 mM) on basal and } \mathrm{K}^{+} \text {-evoked release of } \\ \text { VIP }\end{array} & \begin{array}{l}\text { Concentrations } \\ \text { (mM) }\end{array} & \begin{array}{l}\text { VIP released } \\ \text { (\% of VIP content) }\end{array} \\ \begin{array}{lcc}\text { Agent(s) added } & - & 0.326 \pm 0.017 \\ \text { None } & 1 & 1.413 \pm 0.12^{a} \\ \text { 4-AP } & 7 & 0.273 \pm 0.017 \\ \mathrm{~K}^{+} & 1 & 1.71 \pm 0.155^{b} \\ \quad+4-\mathrm{AP} & 10 & 0.438 \pm 0.03 \\ \mathrm{~K}^{+} & 1 & 2.975 \pm 0.278^{c} \\ \quad+4-\mathrm{AP} & \end{array}\end{array}$

Mouse cerebral cortical slices were incubated as described in Materials and Methods $\mathrm{K}^{+}$concentration under basal conditions was $3 \mathrm{mM}$. VIP released is expressed as percentage of VIP tissue content. Results are the means \pm SEM of 4-12 separate determinations. Absolute values of VIP released into the medium and of VIP content were $9.68 \pm 0.33 \mathrm{pg} / \mathrm{mg}$ prot $(n=12)$ and $3016.88 \pm 116.67 \mathrm{pg} / \mathrm{mg} \mathrm{prot}$ $(n=12)$.

${ }^{a}$ Significantly different from basal VIP release $(p<0.0005)$.

${ }^{b}$ Significantly different from VIP release elicited by $\mathrm{K}^{+}(7 \mathrm{mM})(p<0.0005)$.

${ }^{c}$ Significantly different from VIP release elicited by $\mathrm{K}^{+}(10 \mathrm{~mm})(p<0.0005)$. 


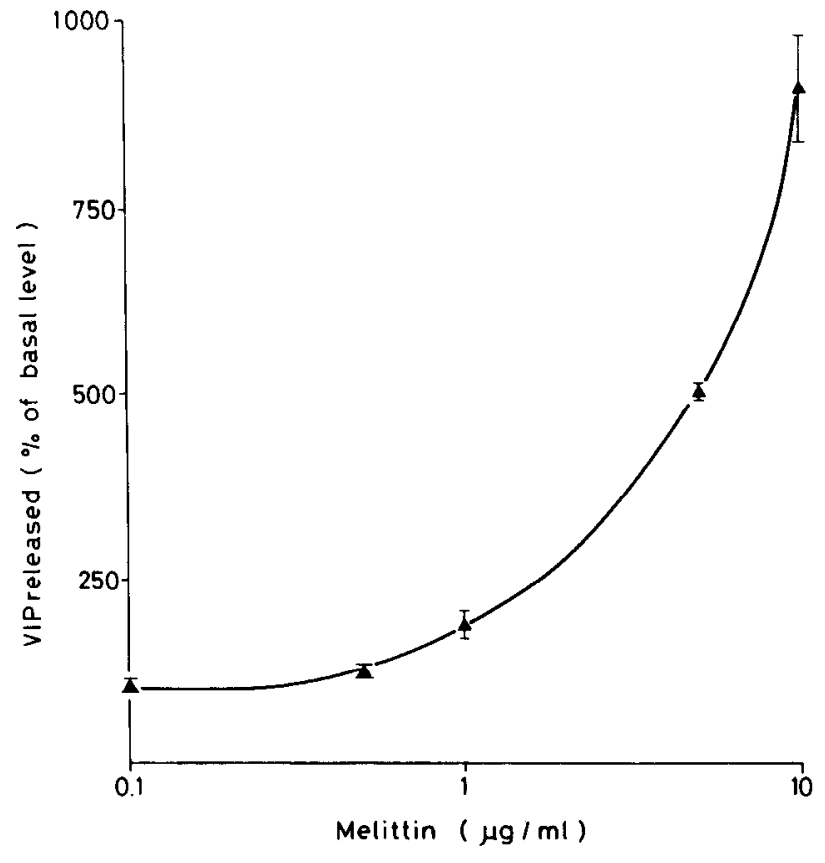

Figure 5. Effect of increasing concentrations of melittin on basal VIP release. Mouse cerebral cortical slices were incubated as described in Materials and Methods. Results are the means \pm SEM of 4 determinations from 2 separate experiments. These results are expressed as percentages of VIP tissue content. Basal VIP release was $0.257 \pm 0.021 \%$, $n=7$. Absolute values of VIP released into the medium and of VIP content were $10.6 \pm 1.29 \mathrm{pg} / \mathrm{mg}$ prot $(n=7)$ and $4092.11 \pm 281.72$ $\mathrm{pg} / \mathrm{mg}$ prot $(n=7)$, respectively. No cross-reactivity was observed in the radioimmunoassay with melittin at a concentration of $10 \mu \mathrm{g} / \mathrm{ml}$.

an activator of $\mathrm{PLA}_{2}$ (Shier, 1979). As shown in Figure 5, melittin promotes a concentration-dependent release of VIP, with significant effects already observed at $1 \mu \mathrm{g} / \mathrm{ml}$.

Through the action of the enzyme, cyclooxygenase prostaglandins and thromboxane are formed from AA, whereas lipoxygenase activity yields leukotrienes from AA. Three inhibitors of lipoxygenase activity, namely ETYA, nordihydroguaiaretic acid (NDGA), and caffeic acid, inhibited in a concentration-dependent manner the release of VIP evoked by 4-AP (Fig. $6 A, B, C$ ), with $\mathrm{IC}_{50}$ of $45 \mu \mathrm{M}, 50 \mu \mathrm{M}$, and $1.5 \mathrm{~mm}$, respectively. Indomethacin, a cyclooxygenase inhibitor (Vane, 1971) that displays at $\mu \mathrm{M}$ concentrations an inhibitory activity towards lipoxygenase (Salmon, 1986; Marshall, 1988), exerted at $100 \mu \mathrm{M}$ a moderate but significant inhibition of VIP release

$\begin{aligned} & \text { Table 2. Lack of effect of mepacrine and caffeic acid on the } \mathrm{K}^{+} \\
& \text {evoked release of VIP }\end{aligned}$
\begin{tabular}{lll} 
Agent(s) added & $\begin{array}{l}\text { Concentration } \\
(\mathrm{mM})\end{array}$ & $\begin{array}{l}\text { VIP released } \\
\text { (\% of VIP content) }\end{array}$ \\
\hline None & - & $0.227 \pm 0.016$ \\
$\mathrm{~K}^{+}$ & 20 & $1.327 \pm 0.089$ \\
+ Mepacrine & 0.05 & $1.342 \pm 0.032^{a}$ \\
+ Caffeic acid & 1 & $1.417 \pm 0.103^{a}$
\end{tabular}

Experimental conditions as in Figures $2-4$ and Table 1, described in detail in Materials and Methods. Results are the means \pm SEM of 3-9 determinations from 2 separate experiments and are expressed as percentages of VIP tissue content. Absolute values of VIP released into the medium and of VIP content were 7.47 $\pm 0.56 \mathrm{pg} / \mathrm{mg}$ prot $(n=9)$ and $3283.68 \pm 85.52 \mathrm{pg} / \mathrm{mg}$ prot $(n=9)$.

${ }^{a}$ Not significantly different from VIP release evoked by $\mathrm{K}^{+}(20 \mathrm{~mm})(p>0.05)$.
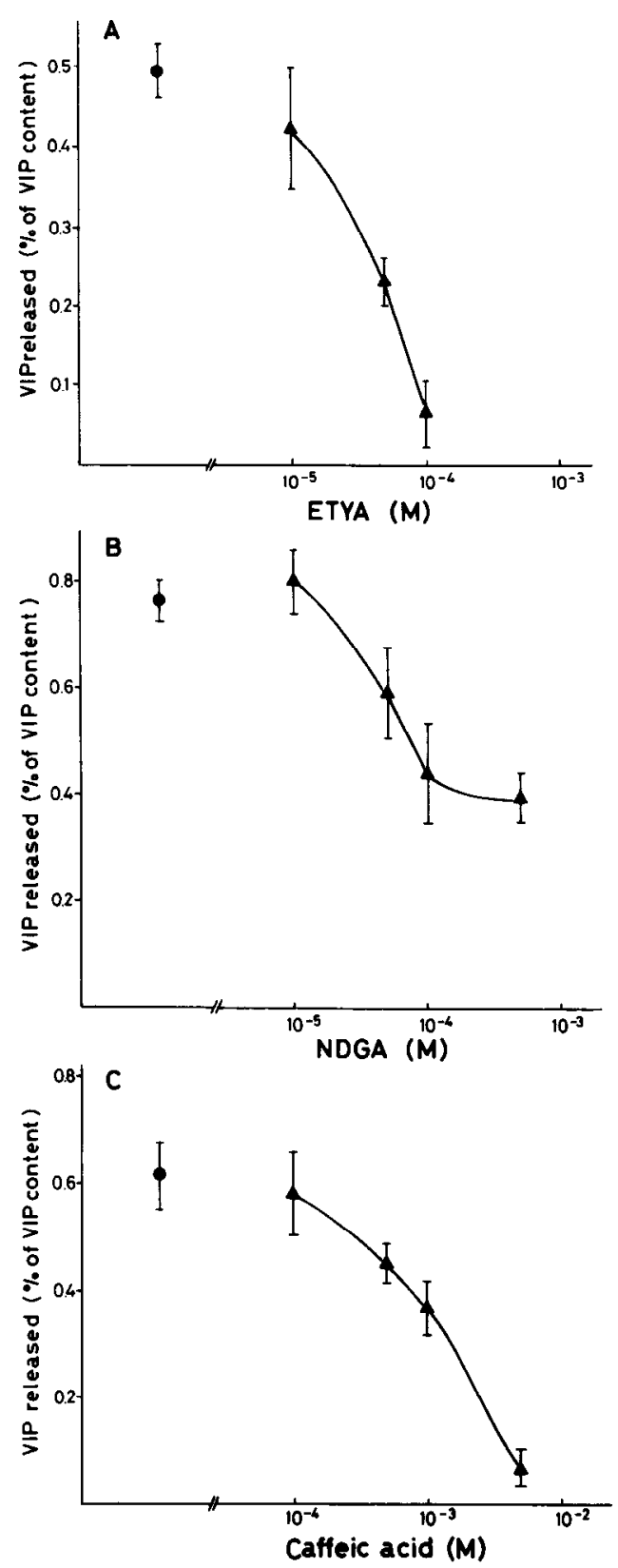

Figure 6. Effect of various lipoxygenase inhibitors, i.e., ETYA, NDGA, and caffeic acid on 4-AP evoked release of VIP. Mouse cerebral cortical slices were incubated as described in Materials and Methods. Results are the means \pm SEM of 4 determinations and are expressed as percentages of VIP tissue content. 4 , Inhibitory effect of ETYA. Basal VIP release was $0.644 \pm 0.049 \%(n=4)$. Absolute values of VIP released into the medium and of VIP content were $20.64 \pm 0.67 \mathrm{pg} / \mathrm{mg}$ prot $(n$ $=4)$ and $3243.04 \pm 183.44 \mathrm{pg} / \mathrm{mg}$ prot $(n=4)$, respectively. $B$, Inhibitory effect of NDGA. Basal VIP release was $0.32 \pm 0.01 \%(n=4)$. Absolute values of VIP released into the medium and of VIP content were $18.36 \pm 1.37 \mathrm{pg} / \mathrm{mg}$ prot $(n=4)$ and $5721.77 \pm 335.98 \mathrm{pg} / \mathrm{mg}$ prot $(n=4)$, respectively. $C$, Inhibitory effect of caffeic acid. Basal VIP release was $0.358 \pm 0.034 \%(n=4)$. Absolute values of VIP released into the medium and of VIP content were $18.46 \pm 1.83 \mathrm{pg} / \mathrm{mg}$ prot $(n$ $=4)$ and $5144.54 \pm 78.82 \mathrm{pg} / \mathrm{mg} \operatorname{prot}(n=4)$ respectively.

evoked by 4-AP. This effect, however, was only marginally additive to that of caffeic acid: basal release (\% of VIP content) $=$ $0.3 \pm 0.03$; 4-AP $(1 \mathrm{mM})=1.55 \pm 0.04 ; 4$-AP $(1 \mathrm{mM})+$ indomethacin $(100 \mu \mathrm{M})=1.08 \pm 0.1 ; 4-\mathrm{AP}(1 \mathrm{mM})+$ caffeic $\operatorname{acid}(500 \mu \mathrm{M})=0.96 \pm 0.03 ;$ and $4-\mathrm{AP} I(\mathrm{mM})+$ indomethacin 


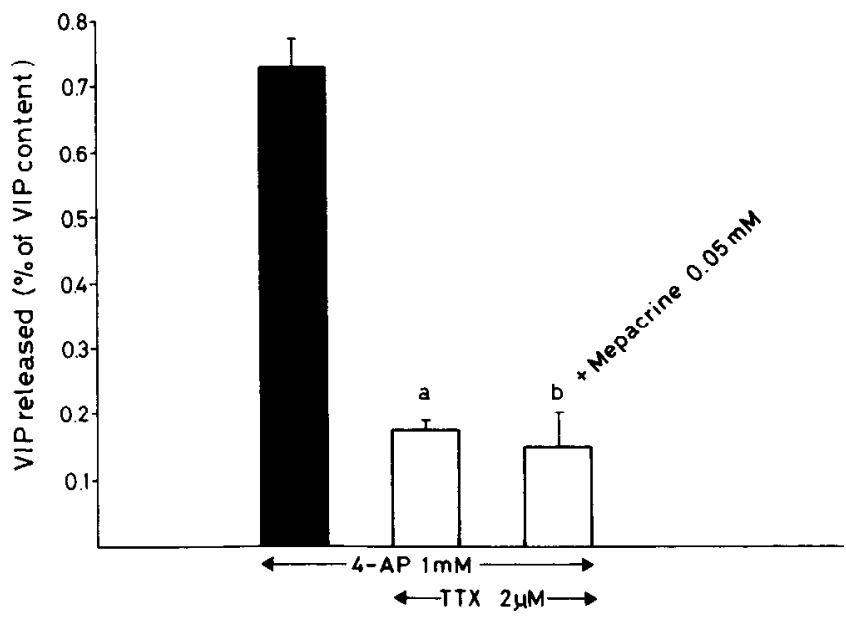

Figure 7. Lack of additive effect of mepacrine on 4-AP-evoked VIP release in the presence of TTX $(2 \mu \mathrm{M})$. Mouse cerebral cortical slices were incubated as described in Materials and Methods. Results are the means \pm SEM of 6-8 determinations from 2 experiments and are expressed as percentages of VIP tissue content. Basal VIP release was $0.209 \pm 0.023 \%(n=8)$. Absolute values of VIP released into the medium and of VIP content were $8.02 \pm 0.76 \mathrm{pg} / \mathrm{mg}$ prot $(n=8)$ and $3900.31 \pm 141 \mathrm{pg} / \mathrm{mg}$ prot $(n=8)$, respectively. $a$, Significantly different from 4-AP- evoked VIP release $(p<0.0005)$. $b$, Not significantly different from 4-AP-evoked VIP release in presence of TTX $(p>0.05)$.

$(100 \mu \mathrm{M})+$ caffeic acid $(500 \mu \mathrm{M})=0.84 \pm 0.02$. It is worth noting that mepacrine $(50 \mu \mathrm{M})$ and caffeic acid $(1 \mathrm{~mm})$ did not inhibit the $\mathrm{K}^{+}$-evoked VIP release (Table 2).

In an attempt to identify the lipoxygenase metabolites involved in the release of VIP evoked by 4-AP, we examined the effect of 5(S)-HPETE and 12(S)-HPETE on basal VIP release. These 2 compounds were, however, without effect (data not shown).

In view of the foregoing observations, we set out to determine whether the inhibition of AA metabolites formation affected preferentially the TTX-sensitive or -insensitive components of the 4-AP-evoked VIP release. Figure 7 shows that the inhibitory effect of mepacrine is not additive to TTX, thus indicating an action on the TTX-sensitive component.

\section{Discussion}

In the series of experiments reported in this article, we have observed that 4-AP promotes a concentration-dependent release of VIP in a $\mathrm{Ca}^{2+}$-sensitive manner. Over $70 \%$ of VIP release elicited by 4-AP is TTX-sensitive. This TTX-sensitive component is mediated by AA metabolites. TTX at $1 \mu \mathrm{M}$ was previously shown to decrease (by $60-68 \%$ ) the release of $\mathrm{ACh}$ elicited by $0.1 \mathrm{~mm}$ 4-AP from rat striatal slices (Dolezal and Tucek, 1983). More recently, Damsma et al. (1988) observed that TTX at $1 \mu \mathrm{M}$ completely blocked the 4 -AP $(0.1 \mathrm{mM})$-induced release of $\mathrm{ACh}$ from striatum of freely moving rats (Damsma et al., 1988).

The existence of a conspicuous component of the 4-AP-evoked VIP release sensitive to TTX indicates that 4-AP increases the occurrence of activatory inputs onto VIP neurons. The basal impulse activity in the slices appears to be quite moderate in view of the absence of inhibitory effect of TTX on basal VIP release (see legend for Fig. 3). However, the TTX sensitivity of the 4-AP-evoked VIP release may in fact reflect the inhibition of the release of one (or more) neurotransmitter(s), from ter- minals impinging on VIP-containing neurons; such neurotransmitter(s) could in turn promote the relcase of VIP through a receptor-mediated mechanism. The observation that the TTXsensitive 4-AP-evoked VIP release is inhibited by agents that block the formation of AA metabolites would support this view, since $\mathrm{PLA}_{2}$ may be activated by receptor-mediated mechanisms (Burch et al., 1986a, b; Axelrod et al., 1988). Furthermore, AA metabolites of the lipoxygenase pathways have recently been shown to regulate presynaptic activity and neurotransmitter release (Piomelli et al., 1987a, b). Thus, in Aplysia sensory neurons the synaptic actions of the neuroactive peptide FMRFamide, which produces presynaptic inhibition of transmitter release, are mediated by lipoxygenase metabolites of AA. This mechanism is supported by observations indicating that membrane hyperpolarization elicited by FMRFamide is abolished after injection of NDGA, a lipoxygenase inhibitor. Furthermore, the response to FMRFamide can be mimicked by the lipoxygenase metabolite 12-HPETE (Piomelli et al., 1987a). In another rcport, Piomelli and colleagues (1987b) reported that in Aplysia the application of histamine and stimulation of the histaminergic neuron $\mathrm{C} 2$ or neurons in the L32 cluster promote the formation of lipoxygenase products of AA, possibly through activation of postsynaptic receptors that are linked to a phospholipase. These results indicate that lipoxygenase metabolites may be second messengers for presynaptic inhibition of these neurons. While supporting a role of AA metabolites in presynaptic release in the mammalian CNS, results reported in the present article, indicate that lipoxygenase products of AA would mediate the stimulation rather than the inhibition of neurotransmitter release in mouse neocortex.

Interestingly, in contrast to what is observed with 4-AP, the $\mathrm{K}^{+}$-evoked release of VIP does not appear to involve AA metabolites, since no effect of mepacrine or caffeic acid is observed (Table 2). $\Lambda$ major difference between $\mathrm{K}^{+}$and 4-AP-evoked VIP release is that the former is not blocked by TTX (Besson et al., 1982; Martin and Magistretti, in press).

In summary, our observations indicate that 4-AP promotes the release of VIP, in part (approximately 30\%) via a direct action on VIP-containing terminals, possibly by activating regenerative $\mathrm{Ca}^{2+}$ currents at this level, and in part (approximately $70 \%$ ) by eliciting the release of one (or more) neurotransmitter(s) that would stimulate VIP release through a $\mathrm{PLA}_{2}$-dependent mechanism

4-AP is known to block at least 2 types of voltage-sensitive $\mathrm{K}^{+}$channels, the delayed rectifier and the A-current (Thompson, 1977; Gustafsson et al., 1982; Hille, 1984; Segal et al., 1984; Rogawski, 1985). Interestingly, actions on the latter current are exerted at $\mu \mathrm{M}$ concentrations of $4-\mathrm{AP}$, whereas at $\mathrm{mM}$ concentrations blockade of the delayed rectifier is apparent (Thompson, 1977; Rogawski, 1985). The concentration-response curve of the release of VIP (Fig. 2) is therefore consistent with an action of 4-AP on A-currents. This view is further supported by 2 sets of observations. First, TEA, which potently blocks the delayed rectifier but considerably less so the A-currents, promotes a marginal release of VIP [VIP release, in \% of content: basal = $0.243 \pm 0.014 ;$ TEA $(10 \mathrm{~mm})=0.398 \pm 0.046]$. Second, analysis of the kinctics of A-currents had indicated that they activate very rapidly following depolarizations ranging from -60 to -45 $\mathrm{mV}$ (Connor and Stevens, 1971; Neher, 1971); they also inactivate rapidly with maintained depolarization. Owing to these properties, A-currents briefly repolarize (because of their rapid kinetics) the membrane potential following small depolar- 
izing stimuli. As shown in Table 1, 4-AP reveals a releasing action of otherwise marginally effective $\mathrm{K}^{+}$concentrations (i.e., small depolarizing stimuli). This observation is consistent with the view that in the absence of 4-AP the depolarization elicited by low $\mathrm{K}^{+}$concentrations and the subsequent $\mathrm{Ca}^{2+}$-dependent VIP release are dampened by the activation of transient outward A-currents. Blockade of these currents by 4-AP would remove this shunt and reveal the releasing effect of low $\mathrm{K}^{+}$concentrations. Similar observations have been made for the glycogenolytic effect of low $\mathrm{K}^{+}$concentrations, which is considerably enhanced by 4 -AP in mouse cerebral cortical slices (Hof et al., 1988).

Finally, the possibility should be considered that at least part of both TTX-sensitive and TTX-insensitive 4-AP-evoked VIP release may be the consequence of a direct effect of the aminopyridine on voltage-sensitive $\mathrm{Ca}^{2+}$ inflow into presynaptic nerve terminals, which would be independent on the blockade of outward $\mathrm{K}^{+}$currents (Lundh and Thesleff, 1977; Illes and Thesleff, 1978; Rogawski and Barker, 1983).

In the rodent neocortex, VIP is contained in bipolar and radially oriented interneurons that branch only minimally in the horizontal plane (Connor and Peters, 1984; Morrison et al., 1984). These morphological characteristics imply that the released VIP molecules will exert their actions locally, within radially restricted cortical domains or columns (Magistretti and Morrison, 1988). Interestingly, it was recently demonstrated that AA metabolites, and more specifically the prostaglandins $E_{2}$ and $F_{2, x}$, strongly potentiate the increases in cAMP levels elicited by VIP in mouse cerebral cortical slices (Schaad et al., 1987). This potentiation most likely represents the molecular mechanism of the synergistic interaction between VIP and noradrenaline in stimulating cAMP formation (Magistretti and Schorderet, 1984, 1985). Taken together, these observations suggest that AA metabolites may play a role in the modulation of VIP-mediated neurotransmission at both presynaptic and postsynaptic sites.

\section{References}

Alvarez-Leefmans, F. J., and R. Miledi (1980) Voltage sensitive calcium entry in frog motoneurones. J. Physiol. (Lond.) 308: 241-257.

Axclrod, J., R. M. Burch, and C. L. Jelsema (1988) Receptor-mediated activation of phospholipase $A_{2}$ via GTP-binding proteins: Arachidonic acid and its metabolites as second messengers. TINS 11:117123.

Besson, J., W. Rotsztejn, B. Poussin, A. M. Lhiaubet, and G. Rosselin (1982) Release of vasoactive intestinal peptide from rat brain slices by various depolarizing agents. Neurosci. Lett. 28: 281-285.

Burch, R. M., A. Luini, D. E. Mais, D. Corda, J. Y. Vanderhoek, L. D. Kohn, and J. Axelrod (1986a) $\alpha_{1}$-Adrenergic stimulation of arachidonic acid release and metabolism in a rat thyroid cell line. J. Biol. Chem. 261: 11236-11241.

Burch, R. M., A. Luini, and J. Axelrod (1986b) Phospholipase $A_{2}$ and phospholipase $\mathrm{C}$ are activated by distinct GTP-binding proteins in response to $\alpha_{1}$-adrenergic stimulation in FRTL5 thyroid cells. Proc. Natl. Acad. Sci. USA 83: 7201-7205.

Chang, J., J. H. Musser, and H. McGregor (1987) Phospholipase A : Function and pharmacological regulation. Biochem. Pharmacol. 36 : 2429-2436.

Connor, J. A., and C. F. Stevens (1971) Voltage clamp studies of a transient outward membrane current in gastropod neural somata. J. Physiol. (Lond.) 213: 21-30.

Connor, J. R., and A. Peters (1984) Vasoactive intestinal polypeptideimmunoreactive neurons in rat visual cortex. Neuroscience 12: 10271044.

Damsma, G., P. T. M. Biessels, B. H. C. Westerink, J. B. De Vries, and A. S. Horn (1988) Differential effects of 4-aminopyridine and 2,4diaminopyridine on the in vivo release of acetylcholine and dopamine in freely moving rats measured by intrastriatal dialysis. Eur. J. Pharmacol. 145: 15-20.

Dolezal, V., and S. Tucek (1983) The effects of 4-aminopyridine and tetrodotoxin on the release of acetylcholine from rat striatal slices. Naunyn-Schmiedeberg's Arch. Pharmacol. 323: 90-95.

Ferron, A., G. R. Siggins, and F. E. Bloom (1985) Vasoactive intestinal polypeptide acts synergistically with norepinephrine to depress spontaneous discharge rate in cerebral cortical neurons. Proc. Natl. Acad. Sci. USA 82: 8810-8812.

Gustafsson, B., M. Galvan, P. Grafe, and H. Wigstrom (1982) A transient outward current in a mammalian central neurone blocked by 4-aminopyridine. Nature 299: 224-254.

Heuser, J. E., T. S. Reese, M. J. Dennis, Y. Jan, L. Jan, and L. Evans (1979) Synaptic vesicle exocytosis captured by quick freezing and correlated with quantal transmitter release. J. Cell Biol. 81: 275-300.

Hille, B. (1984) Ionic Channels of Excitable Membranes, Sinauer, Sunderland, MA.

Hof, P. R., E. Pascale, and P. J. Magistretti (1988) $\mathrm{K}^{+}$at concentrations reachcd in the extraccllular space during neuronal activity promotes a $\mathrm{Ca}^{2+}$-dependent glycogen hydrolysis in mouse cerebral cortex. $\mathrm{J}$. Neurosci. 8: 1922-1928.

Illes, P., and S. Thesleff (1978) 4-Aminopyridine and evoked transmitter release from motor nerve endings. Br. J. Pharmacol. 64: 623629.

Irvine, R. F. (1982) How is the level of free arachidonic acid controlled in mammalian cells? Biochem. J. 204: 3-16.

Jankowska, E., A. Lundberg, P. Rudomin, and E. Sykova (1977) Effects of 4-aminopyridine in excitatory and inhibitory synapses in the spinal cord. Brain Res. 136: 387-392.

Larsson, L. I., J. Fahrenkrug, O. B. Schaffalitzky de Muckadell, F. Sundler, R. Akanson, and J. F. Rehfeld (1976) Localization of vasoactive intestinal polypeptide (VIP) to central and peripheral neurons. Proc. Natl. Acad. Sci. USA 73: 3197-3200.

Lemeignan, M. (1972) Analysis of the action of 4-aminopyridine on the cat lumbar spinal cord. I. Modification of the afferent volley, the monosynaptic discharge amplitude and the polysynaptic evoked responses. Neuropharmacology 11: 551-558.

Llinas, R., K. Walton, and V. Bohr (1976) Synaptic transmission in squid giant synapse after potassium conductance blockage with external 3- and 4-aminopyridine. Biophys. J. 16: 83-86.

Lorén, I., P. C. Emson, J. Fahrenkrug, A. Björklund, J. Alumets, R. Hakanson, and F. Sundler (1979) Distribution of vasoactive intestinal polypeptide in the rat and mouse brain. Neuroscience 4: 19531976.

Lowry, O. H., N. J. Rosebrough, A. L. Farr, and R. J. Randall (1951) Protein measurements with the Folin phenol reagent. J. Biol. Chem. 193: 265-275.

Lundh, H., and S. Thesleff (1977) The mode of action of 4-aminopyridine and guanidine on transmitter release from motor nerve terminals. Eur. J. Pharmacol. 42: 411-412.

Magistretti, P. J., and J. H. Morrison (1988) Noradrenaline- and vasoactive intestinal peptide-containing neuronal systems in neocortex Functional convergence with contrasting morphology. Neuroscience 24: $367-378$.

Magistretti, P. J., and M. Schorderet (1984) VIP and noradrenaline act synergistically to increase cyclic AMP in cerebral cortex. Nature 308: $280-282$

Magistretti, P. J., and M. Schorderet (1985) Norepinephrine and histamine potentiate the increases in cAMP elicited by Vasoactive Intestinal Polypeptide in mouse cerebral cortical slices: Mediation by $\alpha_{1}$-adrenergic and $\mathrm{H}_{1}$-histaminergic receptors. J. Neurosci. 5: 362368.

Magistretti, P. J., J. H. Morrison, W. J. Shoemaker, V. Sapin, and F. E. Bloom (1981) Vasoactive intestinal polypeptide induces glycogenolysis in mouse cortical slices: A possible regulatory mechanism for the local control of energy metabolism. Proc. Natl. Acad. Sci. USA 78: 6535-6539.

Marshall, L. A. (1988) Arachidonic acid metabolism of cultured peritoneal rat macrophages and its manipulation by nonsteroidal antiinflammatory agents. Immunopharmacology 15: 177-187.

Martin, J.-L., and P. J. Magistretti (in press) Pharmacological studies of voltage-sensitive $\mathrm{Ca}^{2+}$-channels involved in the release of vasoactive intestinal peptide evoked by $\mathrm{K}^{+}$in mouse central cortical slices. Neuroscience.

Martin, J.-L., K. Rose, G. H. Hughes, and P. J. Magistretti (1986) [mono[ $\left.{ }^{125} \mathrm{I}\right]$ iodo-Tyr ${ }^{10}, \mathrm{MetO}^{17}$ ]-Vasoactive Intestinal Polypeptide: 
Preparation, characterization, and use for radioimmunoassay and receptor binding. J. Biol. Chem. 261: 5320-5327.

Molgo, J., H. Lundh, and S. Thesleff (1980) Potency of 3,4-aminopyridine and 4-aminopyridine on mammalian neuromuscular transmission and the effect of pH changes. Eur. J. Pharmacol. 61: 25-34.

Moore, J. W., M. P. Blaustein, N. C. Anderson, and T. Narahashi (1967) Basis of tetrodotoxin's selectivity in blockage of squid axons. J. Gen. Physiol. 50: 1401-1411.

Morrison, J. H., P. J. Magistretti, R. Benoitt, and F. E. Bloom (1984) The distribution and morphological characteristics of the intracortical VIP-positive cell: An immunohistochemical analysis. Brain Res. 292: 269-282.

Neher, E. (1971) Two fast transient current components during voltage clamp on snail neurons. J. Gen. Physiol. 58: 36-53.

Phillis, J. W., J. R. Kirkpatrick, and S. I. Said (1978) Vasoactive intestinal polypeptide excitation of central neurons. Can. J. Physiol. Pharmacol. 56: 337-340.

Piomelli, D., A. Volterra, N. Dale, S. A. Siegelbaum, E. R. Kandel, J. H. Schwartz, and F. Belardetti (1987a) Lipoxygenase metabolites of arachidonic acid as second messengers for presynaptic inhibition of Aplysia sensory cells. Nature 328: $38-43$.

Piomelli, D., E. Shapiro, S. J. Feinmark, and J. H. Schwartz (1987b) Metabolites of arachidonic acid in the nervous system of Aplysia: Possible mediators of synaptic modulation. J. Neurosci. 7: 36753686 .

Quik, M., L. L. Iversen, and S. R. Bloom (1978) Effect of vasoactive intestinal peptide (VIP) and other peptides on cAMP accumulation in rat brain. Biochem. Pharmacol. 27: 2209-2213.

Rogawski, M. A. (1985) The A-current: How ubiquitous a feature of excitable cells is it? TINS $8: 214-219$

Rogawski, M. A., and J. L. Barker (1983) Effects of 4-aminopyridine on calcium action potentials and calcium current under voltage clamp in spinal neurons. Brain Res. 280: 180-185.
Said, S. I., and V. Mutt (1970) Polypeptide with broad biological activity: Isolation from small intestine. Science 169: 1217-1218.

Salmon, J. A. (1986) Inhibition of prostaglandin, thromboxane and leukotriene biosynthesis. Adv. Drug Res. 15: 111-167.

Schaad, N., M. Schorderet, and P. J. Magistretti (1987) Prostaglandins and the synergism between VIP and noradrenaline in the cerebral cortex. Nature 328: 637-640.

Segal, M., M. A. Rogawski, and J. L. Barker (1984) A transient potassium conductance regulates the excitability of cultured hippocampal and spinal neurons. J. Neurosci. 4: 604-609.

Shier, W. T. (1979) Activation of high levels of endogenous phospholipase A2 in cultured cells. Proc. Natl. Acad. Sci. USA 76: 195199.

Thesleff, S. (1980) Aminopyridines and synaptic transmission. Neuroscience 5: 1413-1419.

Thompson, S. H. (1977) Three pharmacologically distinct potassium channels in molluscan neurones. J. Physiol. (Lond.) 265: 465-488.

Ulbricht, W. (1974) Drugs to explore the ionic channels in the axon membrane. In Biochemistry of Sensory Functions, L. Jaenicke, ed., pp. 351-365, Springer, Berlin.

Vane, J. R. (1971) Inhibition of prostaglandin synthesis as a mechanism of action for aspirin-like drugs. Nature 231: 232-235.

Wang, J.-Y., T. L. Yaksh, and V. L. W. Go (1983) In vivo studies on the basal and evoked release of cholecystokinin and vasoactive intestinal polypeptide from cat cerebral cortex and periventricular structures. Brain Res. 280: 105-117.

Wang, J.-Y., T. L. Yaksh, and V. L. W. Go (1985) Studies on the in vivo releases of vasoactive intestinal polypeptide (VIP) from the cerebral cortex: Effects of cortical, brainstem and somatic stimuli. Brain Res. 326: 317-334. 